\title{
Tumor Necrosis Factor Enhances the Capsaicin Sensitivity of Rat Sensory Neurons
}

\author{
Grant D. Nicol, ${ }^{1}$ John C. Lopshire, ${ }^{2}$ and Carl M. Pafford ${ }^{2}$ \\ ${ }^{1}$ Department of Pharmacology and Toxicology and ${ }^{2}$ Medical Neurobiology Program, School of Medicine, Indiana \\ University, Indianapolis, Indiana 46202-5120
}

The capacity of the proinflammatory cytokines, tumor necrosis factor $\alpha(\mathrm{TNF} \alpha)$ and interleukin $1 \beta(\mathrm{IL}-1 \beta)$, to modulate the sensitivity of isolated sensory neurons grown in culture to the excitatory chemical agent capsaicin was examined. Alterations in capsaicin sensitivity were assessed by quantifying the number of neurons labeled with cobalt after exposure to capsaicin and by recording the whole-cell response from a single neuron to the focal application of capsaicin. A $24 \mathrm{hr}$ pretreatment of the neuronal cultures with TNF $\alpha$ (10 or $50 \mathrm{ng} / \mathrm{ml}$ ), but not IL-1 $\beta$ (10 or $50 \mathrm{ng} / \mathrm{ml})$, produced a concentration-dependent increase in the number of cobalt-labeled neurons after exposure to $100 \mathrm{nM}$ capsaicin. The peak increase in the number of labeled neurons was attained after a $4 \mathrm{hr}$ treatment with $10 \mathrm{ng} / \mathrm{ml}$ TNF $\alpha$. Similarly, pretreatment with TNF $\alpha(10 \mathrm{ng} / \mathrm{ml}$ for 4,12 , and $24 \mathrm{hr})$ produced a greater than twofold increase in the average peak amplitude of the inward current evoked by 100 nм capsaicin.
Both the TNF $\alpha$-induced increase in labeling and current amplitude were blocked by treating the neuronal cultures with indomethacin before the addition of TNF $\alpha$. Enhancement of the capsaicin-evoked current also was blocked by the specific cyclo-oxygenase-2 inhibitor SC-236. These results indicate that TNF $\alpha$ can enhance the sensitivity of sensory neurons to the excitation produced by capsaicin and that this enhancement likely is mediated by the neuronal production of prostaglandins. Isolated sensory neurons grown in culture may prove to be a useful model system in which to explore how prolonged exposure to mediators associated with chronic inflammation alter the regulatory pathways that modulate the excitability of the nervous system.

Key words: tumor necrosis factor $\alpha$; interleukin $1 \beta$; capsaicin; sensitization; prostaglandins; cyclo-oxygenase-2; membrane excitability
Tumor necrosis factor $\alpha$ and interleukin $1 \beta$ serve as potent intermediaries between tissue injury and the resulting physiological indices of inflammation, such as neutrophil activation, plasma extravasation, and vasodilatation (Dinarello, 1987, 1991; Le and Vilček, 1987; Kimball, 1991). In rheumatoid arthritis, a well characterized pathology exemplifying the effects of chronic inflammation, the levels of tumor necrosis factor $\alpha(\mathrm{TNF} \alpha)$ and interleukin $1 \beta$ (IL-1 $\beta$ ) are elevated in synovial fluid (Dayer and Demczuk, 1984; Arend and Dayer, 1990; Feldman et al., 1990). In animal models of synovitis, injection of TNF $\alpha$ or IL- $1 \beta$ into the joints produces many of the symptoms observed with rheumatoid arthritis (Arend and Dayer, 1990). The responses associated with inflammation include a heightened sensitivity to painful stimuli, a condition known as hyperalgesia (Treede et al., 1992). Indeed, in animal models of peripheral hyperalgesia, the injection of IL- $1 \beta$ or TNF $\alpha$ lowers the response threshold to noxious stimulation (Ferreira et al., 1988; Schweizer et al., 1988; Follenfant et al., 1989; Cunha et al., 1992).

Although the cellular mechanisms whereby TNF $\alpha$ and IL-1 $\beta$ enhance the sensitivity to noxious stimuli are unknown, this sen-

Received Oct. 31, 1996; accepted Nov. 18, 1996.

This work was supported by National Institutes of Health Grant RO1-NS30527 (G.D.N.). J.C.L. was supported by the Indiana University Purdue University, Indianapolis (IUPUI) Research Investment Fund; C.M.P. was supported by the IUPUI Research Investment Fund and an Indiana Medical Scholar Fellowship. We are grateful to Drs. Michael Vasko and Angela Evans for discussions about signal transduction in sensory neurons. We thank Dr. Peter Isakson for the generous gift of SC-236.

Correspondence should be addressed to Dr. G. D. Nicol, Department of Pharmacology and Toxicology, School of Medicine, Indiana University, 635 Barnhill Drive, Indianapolis, IN 46202-5120.

Copyright (C) 1997 Society for Neuroscience $0270-6474 / 97 / 170975-08 \$ 05.00 / 0$ sitization may involve prostaglandins. Both $\mathrm{TNF} \alpha$ and IL- $1 \beta$ enhance the release of arachidonic acid and the synthesis of eicosanoids, especially prostaglandin $\mathrm{E}_{2}\left(\mathrm{PGE}_{2}\right.$; Dayer et al., 1985), via the induction of phospholipase $\mathrm{A}_{2}$ and cyclo-oxygenase activities, respectively (Chang et al., 1986; Burch et al., 1988; Raz et al., 1988; Burch and Tiffany, 1989). The cytokine-induced release of $\mathrm{PGE}_{2}$ may sensitize cells and thus potentiate the response to other inflammatory agents, such as bradykinin (Higgs et al., 1984; Salmon and Higgs, 1987; Smith, 1992). Indeed, previous injection of $\mathrm{PGE}_{2}$ into a rat's hind paw decreases the withdrawal time in response to noxious stimulation (Ferreira et al., 1978). Similarly, in single unit recordings from sensory nerves, pretreatment with $\mathrm{PGE}_{2}$ increases the firing activity evoked by either bradykinin (Handwerker, 1976; Mense, 1981) or mechanical stimulation (Pateromichelakis and Rood, 1982; Heppelmann et al., 1985). Furthermore, in isolated sensory neurons grown in culture, the number of action potentials elicited by either elevated potassium concentration or focally applied bradykinin is increased after pretreatment with $\mathrm{PGE}_{2}$ (Baccaglini and Hogan, 1983; Nicol and Cui, 1994). Thus, the sensitizing actions of $\mathrm{PGE}_{2}$ are directly on the sensory neuron.

Therefore, to determine whether the enhanced sensitivity produced by the proinflammatory cytokines TNF $\alpha$ or IL- $1 \beta$ results from a direct action on the sensory neurons or via a secondary mediator, we examined the excitation produced by capsaicin in embryonic rat sensory neurons grown in culture as a measure of neuronal sensitivity. Capsaicin was used because it selectively stimulates most, but not all, C-fibers and some A $\delta$ fibers, the neurons associated with nociceptive signaling and neurogenic inflammation (Holzer, 1991). Capsaicin activates a nonselective 
cationic channel that gives rise to an inward current (Heyman and Rang, 1985; Marsh et al., 1987; Bevan and Forbes, 1988; Wood et al., 1988). Activation of this channel by capsaicin in the presence of extracellular cobalt results in the labeling of sensory neurons; therefore, putative nociceptive neurons can be distinguished from other neurons in a given population (Wood et al., 1988; Hingtgen and Nicol, 1994). In this report we demonstrate that pretreatment with $\mathrm{TNF} \alpha$, but not IL- $1 \beta$, increased the number of neurons labeled with cobalt after exposure to capsaicin. Furthermore, the peak amplitude of the capsaicin-evoked current produced by submaximal concentrations was enhanced after treatment with $\mathrm{TNF} \alpha$. These findings suggest that $\mathrm{TNF} \alpha$ can directly enhance the sensitivity of sensory neurons to excitatory chemical agents.

\section{MATERIALS AND METHODS}

Isolation and culture of embryonic rat sensory neurons. The procedures for isolation and culture of rat sensory neurons have been described previously (Vasko et al., 1994). Briefly, the dorsal root ganglia (DRG) from E15-E17 fetal rats were dissected free and placed in a dish containing sterile calcium-free, magnesium-free HBSS at $4^{\circ} \mathrm{C}$. The DRGs were incubated in HBSS containing $0.025 \%$ trypsin for $25 \mathrm{~min}$ at $37^{\circ} \mathrm{C}$. The digestion was terminated with the addition of $0.25 \%$ trypsin inhibitor; then the cells were washed and centrifuged. Ganglia were washed once with HBSS and then resuspended in DMEM (Life Technologies, Grand Island, NY) supplemented with $2 \mathrm{~mm}$ glutamine, $50 \mu \mathrm{g} / \mathrm{ml}$ penicillin and streptomycin, $10 \%$ heat-inactivated fetal bovine serum, $50 \mu \mathrm{M}$ 5-fluoro2'-deoxyuridine, $150 \mu \mathrm{M}$ uridine, and $250 \mathrm{ng} / \mathrm{ml} 7 \mathrm{~S}$-nerve growth factor (Harlan Bioproducts for Science, Indianapolis, IN). Individual cells were obtained by mechanical agitation with a fire-polished pipette until a cloudy suspension was observed. For the cobalt-labeling studies, $\sim 300,000$ cells were plated into each well ( $35 \mathrm{~mm}$ diameter) of a six well Falcon culture dish coated with poly-D-lysine $(100 \mu \mathrm{g} / \mathrm{ml}$ in sterile water $)$. For the electrophysiological recordings, $\sim 300,000$ cells were plated in a collagen-coated culture dish containing small plastic coverslips. Cells were grown at $37^{\circ} \mathrm{C}$ in a $5 \% \mathrm{CO}_{2}$ atmosphere, and the medium was changed every $2 \mathrm{~d}$. These procedures have been approved by the Animal Care and Use Committee of Indiana University School of Medicine.

Cobalt labeling of sensory neurons. These experiments were performed via methods that have been described previously (Hingtgen and Nicol, 1994). Briefly, after $5 \mathrm{~d}$ in culture, cells were washed with normal Ringer's solution of the following composition (in $\mathrm{mM}$ ): $140 \mathrm{NaCl}, 5 \mathrm{KCl}, 2 \mathrm{CaCl}_{2}$, $1 \mathrm{MgCl}_{2}, 10$ HEPES, and 10 glucose, $\mathrm{pH}$ at 7.4 with $\mathrm{NaOH}$. Then cells were exposed to Ringer's solution containing $100 \mathrm{~nm}$ capsaicin and $10 \mathrm{~mm}$ $\mathrm{CoCl}_{2}$ for $8 \mathrm{~min}$. The capsaicin-cobalt Ringer's solution was removed, the cells were washed with Ringer's solution, and then the cells were exposed to Ringer's solution containing $1 \%$ ammonium sulfide for $5 \mathrm{~min}$. After the cobalt precipitation, cells were washed with PBS $(100 \mathrm{~mm}$ $\mathrm{NaH}_{2} \mathrm{PO}_{4}$ and $155 \mathrm{~mm} \mathrm{NaCl}, \mathrm{pH} 7.4$ ) and fixed with $4 \%$ paraformaldehyde in PBS for $20 \mathrm{~min}$. The cobalt staining was enhanced by incubating the cells in a developer solution ( $15 \mathrm{~mm}$ hydroquinone, $38 \mathrm{~mm}$ citric acid, and $280 \mathrm{~mm}$ sucrose) for $15 \mathrm{~min}$ at $60^{\circ} \mathrm{C}$. Then the cells were exposed to developer containing $0.1 \%(\mathrm{w} / \mathrm{v}) \mathrm{AgNO}_{3}$ for $\sim 30 \mathrm{~min}$ at $60^{\circ} \mathrm{C}$. The intensity of the staining was inspected visually, and enhancement was stopped by washing the cells with fresh developer. Neuronal staining was determined by counting the number of positive (dark-brown staining) and negative (clear or yellowish) cells in five random fields per well $(\sim 80-100$ cells per field) from dishes of neuronal cultures established on at least three different days.

To examine the effects of TNF $\alpha$ or IL- $1 \beta$ on the capsaicin sensitivity of these sensory neurons, we pretreated cell cultures with various concentrations of these agents for various times before exposure to capsaicin (day 4 in culture). Untreated cultures obtained from the same neuronal harvest served as the control cells for both the labeling and electrophysiological studies. In those experiments examining the effects of cyclooxygenase inhibition on the actions of TNF $\alpha$, neuronal cultures were treated with either indomethacin or SC-236 (a specific cyclo-oxygenase-2 inhibitor) for $1 \mathrm{hr}$ before the addition of TNF $\alpha$. To explore the effects of carba prostacyclin $\left(\mathrm{CPGI}_{2}\right.$, a nonhydrolyzable analog of prostacyclin or prostaglandin $\mathrm{I}_{2}$ ) alone or in combination with TNF $\alpha$ on the capsaicincobalt loading, cells were exposed to $10 \mathrm{nM} \mathrm{CPGI}_{2}$ or $10 \mathrm{nM} \mathrm{CPGI}_{2}$ and $10 \mathrm{ng} / \mathrm{ml} \mathrm{TNF} \alpha$ for $24 \mathrm{hr}$ before exposure to capsaicin and cobalt.

Electrophysiology. The procedures for whole-cell patch-clamp record- ings of rat sensory neurons have been described in detail previously (Nicol and Cui, 1994). Briefly, a coverslip with the DRG neurons (5 d in culture) was placed in a recording chamber, where the neurons were superfused with normal Ringer's solution. Using the whole-cell patchclamp technique (Hamill et al., 1981), we recorded membrane currents from a holding potential of $-60 \mathrm{mV}$ with a List EPC-7 (List Electronic, Darmstadt, Germany) patch-clamp amplifier. Recording pipettes were pulled from borosilicate disposable pipettes and had resistances of 3-5 $\mathrm{M} \Omega$ when filled with the following solution (in $\mathrm{mM}$ ): $140 \mathrm{KCl}, 5 \mathrm{MgCl}_{2}, 4$ ATP, 0.3 GTP, $2.5 \mathrm{CaCl}_{2}$, 5 EGTA (calculated free $\mathrm{Ca}^{2+}$ concentration of $100 \mathrm{nM}$ ), and $10 \mathrm{HEPES}$, at $\mathrm{pH} 7.2$ with $\mathrm{KOH}$. The cell capacitance was compensated by the nulling circuitry of the recording amplifier.

Capsaicin was applied focally to the neuron by placing a pipette (5-10 $\mu \mathrm{m}$ in diameter) filled with Ringer's solution containing $100 \mathrm{~nm}$ capsaicin and $1 \mathrm{~mm}$ trypan blue within 10-30 $\mu \mathrm{m}$ of the cell body. Then positive pressure was applied to the pipette to eject the solution for which trypan blue served to visualize this process. The focal application of trypan blue alone had no effect on these sensory neurons (Nicol and Cui, 1994). Capsaicin was diluted to a concentration of $100 \mathrm{nM}$, because this value is slightly less than the $\mathrm{EC}_{50}$ obtained for the concentration-response relation for capsaicin in embryonic sensory neurons (J. C. Lopshire and G. D. Nicol, unpublished observations). While continuously superfusing the bath with Ringer's solution, we obtained two responses, separated by $\sim 2$ min, to the focal application of $100 \mathrm{~nm}$ capsaicin. After obtaining the test responses, we changed the superfusate to a Ringer's solution containing $1 \mu \mathrm{M}$ capsaicin to determine the maximal response. Responses from only a single neuron were obtained from each coverslip to avoid any possible desensitization that might occur after the application of $1 \mu \mathrm{M}$ capsaicin. All experiments were done at room temperature $\left(\sim 23^{\circ} \mathrm{C}\right)$.

Only the results obtained from neurons that satisfied the following criteria are presented in this report. First, after establishing the whole-cell configuration, neurons had to maintain zero-current potentials more hyperpolarized than $-45 \mathrm{mV}$ for at least $4-5 \mathrm{~min}$ before setting the holding potential to $-60 \mathrm{mV}$. Second, the amplitudes of the two responses obtained to the focal application of $100 \mathrm{~nm}$ capsaicin had to be within $\pm 10 \%$ of their average value.

Analysis. Statistical differences among the numbers of neurons labeled with cobalt for the various experimental treatments were determined by a $\chi^{2}$ analysis. In this set of studies, one or two wells of cells from each neuronal harvest served as a control group for each experimental treatment. To determine significance for each experimental treatment relative to their respective controls, we obtained a $\chi^{2}$ value for each contingency table. The amplitudes of the inward currents elicited by two applications of $100 \mathrm{nM}$ capsaicin were averaged to obtain the mean response to capsaicin. To account for the varying sensitivity of different sensory neurons to capsaicin, we normalized the mean response to the maximal response obtained with the bath application of $1 \mu \mathrm{M}$ capsaicin. Statistical differences between the control recordings and those obtained under various treatment conditions were determined by one-way ANOVA. When a significant difference was obtained, a Student-Newman-Keuls or Dunnett's post hoc test was performed. Values of $p<0.05$ were judged to be statistically significant.

Chemicals. Carba prostacyclin was obtained from Cayman Chemical (Ann Arbor, MI); tumor necrosis factor- $\alpha$ and interleukin-1 $\beta$ (recombinant murine) were obtained from R \& D Systems (Minneapolis, MN). The cyclo-oxygenase-2 inhibitor SC-236 was a generous gift of Dr. Peter Isakson (G. D. Searle, St. Louis, MO). All other chemicals were obtained from Sigma (St. Louis, MO). Carba prostacyclin, capsaicin, and SC-236 were dissolved in 1-methyl-2-pyrrolidinone (HPLC grade, Aldrich, Milwaukee, WI) to obtain concentrated stock solutions. Then these stock solutions were diluted with Ringer's solution to yield the appropriate concentration.

\section{RESULTS}

\section{Tumor necrosis factor enhances the number of capsaicin-sensitive neurons}

Previously, we demonstrated that capsaicin selectively labeled with cobalt the small-diameter sensory neurons isolated from the dorsal root ganglia of embryonic rats (Hingtgen and Nicol, 1994). In the present study, the capacity of the proinflammatory cytokines, tumor necrosis factor $\alpha(\mathrm{TNF} \alpha)$ and interleukin-1 $\beta$ (IL$1 \beta$ ), to modulate the sensitivity of isolated sensory neurons to the excitatory agent capsaicin was examined by quantifying the num- 
ber of neurons labeled with cobalt after treatment with capsaicin. Under control conditions, the average percentage of cells labeled by $100 \mathrm{~nm}$ capsaicin was $15.5 \pm 1.2 \%$ (range $10-26 \% ; n=14$ neuronal harvests), indicating that, from preparation to preparation, $100 \mathrm{~nm}$ capsaicin labeled a relatively stable number of cells from the total neuronal population. As illustrated in Figure 1, pretreatment with $\mathrm{TNF} \alpha$ enhanced the number of capsaicinsensitive neurons (Fig. $1 A$ ), whereas IL-1 $\beta$ was without effect (Fig. $1 C$ ). After a $24 \mathrm{hr}$ pretreatment with $\mathrm{TNF} \alpha$, the number of capsaicin-sensitive neurons was increased in a concentrationdependent manner. TNF $\alpha$ at $1 \mathrm{ng} / \mathrm{ml}$ did not enhance the number of positively stained neurons (36 of 292 neurons, $12.3 \%$ positively labeled), whereas the number was increased significantly by twofold for $10 \mathrm{ng} / \mathrm{ml}$ (883 of 2556 neurons, 34.5\% labeled) and 50 $\mathrm{ng} / \mathrm{ml} \mathrm{TNF} \alpha$ (448 of 970 neurons, $46.2 \%$ labeled). In another series of experiments, the time course of the TNF $\alpha$-induced sensitization was determined. As illustrated in Figure $1 B$, it appeared that the maximal increase in the number of labeled neurons $(27.3 \%, 163$ of 597 neurons) was attained after a $4 \mathrm{hr}$ treatment with $10 \mathrm{ng} / \mathrm{ml} \mathrm{TNF} \alpha$. Similar values for the number of labeled neurons were observed after $12 \mathrm{hr}(25.7 \%, 177$ of 689 neurons) and $24 \mathrm{hr}$ exposures $(26.7 \%, 172$ of 645 neurons). In contrast to the sensitization produced by $\mathrm{TNF} \alpha$, only $17.7 \%$ (91 of 514 neurons) and $12.6 \%$ (101 of 799 neurons) of the neurons were labeled with cobalt after a $24 \mathrm{hr}$ exposure to 10 and $50 \mathrm{ng} / \mathrm{ml}$ IL-1 $\beta$, respectively (Fig. $1 C$ ). In control experiments, sensory neurons exposed to either $100 \mathrm{~nm}$ capsaicin in the absence of cobalt or $10 \mathrm{~mm} \mathrm{CoCl}_{2}$ in the absence of capsaicin produced no labeling (data not shown).

In many instances, the physiological actions of cytokines are believed to be intertwined with prostaglandins. This interdependency may result from either a cytokine-mediated activation of the cyclo-oxygenase pathway, i.e., the production of prostaglandins (Dayer et al., 1985; Burch et al., 1988; Burch and Tiffany, 1989), or prostaglandins may act synergistically to enhance the actions of the cytokine (Burch and Tiffany, 1989). To investigate the possibility that prostaglandins mediated the $\mathrm{TNF} \alpha$-induced increase in labeled neurons, we pretreated cell cultures with $30 \mu \mathrm{M}$ indomethacin, a nonselective blocker of cyclo-oxygenase activity, for $1 \mathrm{hr}$ before the addition of TNF $\alpha$ to the cultures. As shown in Figure $2 A$, indomethacin blocked the sensitization produced by $\mathrm{TNF} \alpha$. The number of labeled neurons was reduced significantly from a value of $28.6 \%$ after treatment with $\mathrm{TNF} \alpha$ to $17 \%$ after indomethacin and $\mathrm{TNF} \alpha$ (189 of 1114 neurons). Exposure to $30 \mu \mathrm{M}$ indomethacin alone had no significant effect on the number of labeled neurons (125 of 937 neurons, $13.3 \%$ positive).

Another series of experiments examined the possibility that the $\mathrm{TNF} \alpha$-induced sensitization might be enhanced further by cotreatment with a prostaglandin. Neuronal cultures were treated with $10 \mathrm{nM} \mathrm{CPGI}_{2}$ alone or in combination with $10 \mathrm{ng} / \mathrm{ml} \mathrm{TNF} \alpha$ for $24 \mathrm{hr}$. This concentration was chosen because a previous study demonstrated that $10 \mathrm{nM} \mathrm{CPGI}_{2}$ produced a two- to threefold enhancement in the release of substance $\mathrm{P}$ or calcitonin generelated peptide (CGRP) when sensory neurons grown in culture were stimulated by capsaicin (Hingtgen and Vasko, 1994). As illustrated in Figure $2 \mathrm{~B}, \mathrm{CPGI}_{2}$ alone significantly increased the number of labeled neurons to $38.1 \%$ (463 of 1216 neurons). The combination of $\mathrm{CPGI}_{2}$ and $\mathrm{TNF} \alpha$ had no additional effect on the increase in neuronal number (510 of 1251 neurons, $40.8 \%$ positive), as compared with $\mathrm{TNF} \alpha$ alone ( $41.8 \%$ positive). It does not seem likely that values between 30 and $40 \%$ were maximal,
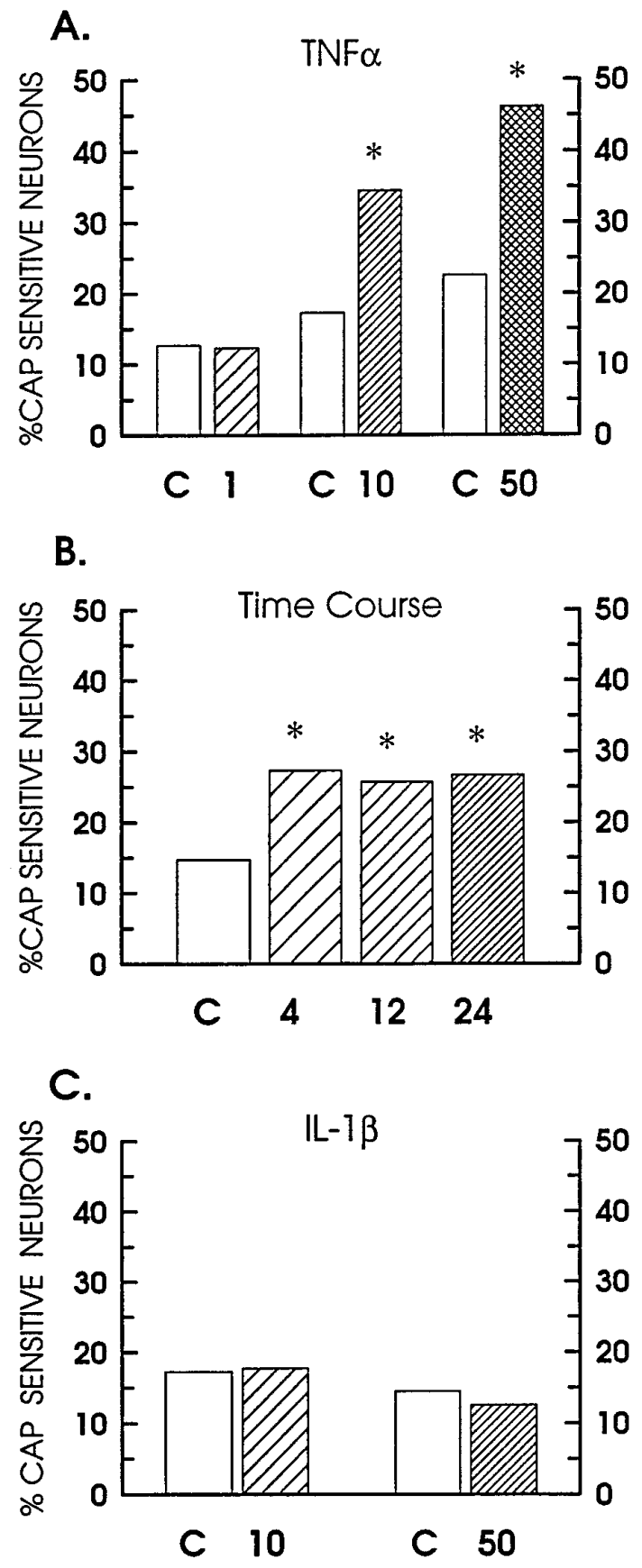

Figure 1. TNF $\alpha$ increases the number of neurons labeled with cobalt after exposure to $100 \mathrm{~nm}$ capsaicin. The percentage of labeled neurons for each control condition is represented by the open bars. $A$, The percentage of neurons positively labeled with cobalt after a $24 \mathrm{hr}$ pretreatment with TNF $\alpha$. The hatched bars represent the percentages obtained for the following concentrations of TNF $\alpha: 1 \mathrm{ng} / \mathrm{ml}$ (coarse), $10 \mathrm{ng} / \mathrm{ml}$ (medium), or $50 \mathrm{ng} / \mathrm{ml}$ (crossed). B. Time course for the sensitization produced by treatment with $10 \mathrm{ng} / \mathrm{ml} \mathrm{TNF} \alpha$ for the indicated times in hours. These experiments were performed in a set of neurons that differed from those shown in $A$. $C$, The percentage of neurons that were positively labeled after a $24 \mathrm{hr}$ pretreatment with 10 and $50 \mathrm{ng} / \mathrm{ml}$ of IL $1 \beta$, shown as the coarse- and fine-hatched bars, respectively. The asterisks indicate a statistical difference at $p<0.05$.

because previous work in adult, neonatal, or embryonic sensory neurons demonstrated that, with a higher concentration of capsaicin $(1 \mu \mathrm{M}),>50 \%$ of the neurons can be labeled with cobalt (Winter, 1987; Wood et al., 1988; Hingtgen and Nicol, 1994). 
A.

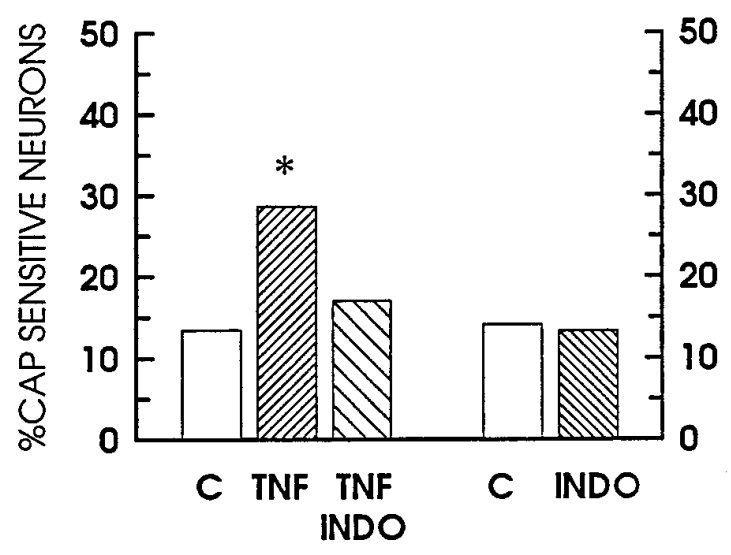

B.

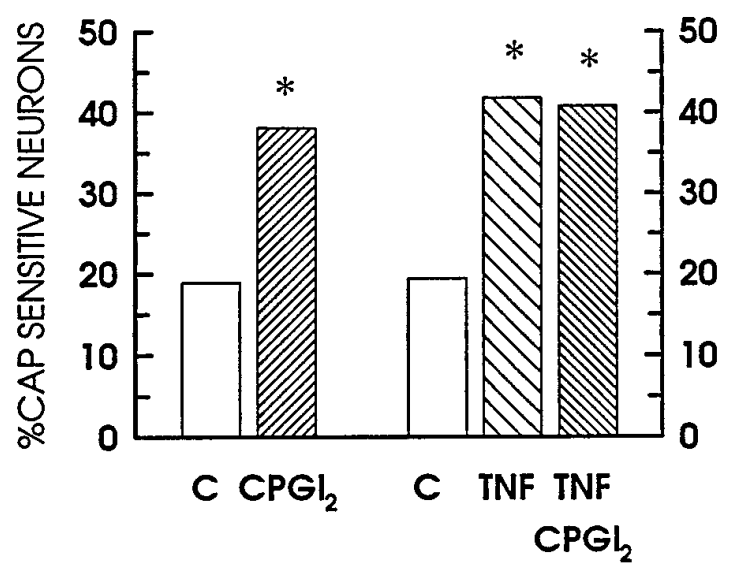

Figure 2. Indomethacin blocks the TNF $\alpha$-induced increase in labeled neurons. These data represent the percentage of neurons labeled with cobalt after exposure to $100 \mathrm{~nm}$ capsaicin. The open bars show the percentage of neurons obtained for the various control conditions. $A$, Suppression of the TNF $\alpha$-mediated enhancement of labeling by indomethacin. The fine-hatched bar, labeled $T N F$, represents the percentage after a 24 pretreatment with $10 \mathrm{ng} / \mathrm{ml} \mathrm{TNF} \alpha$; the coarse-hatched bar, labeled TNF INDO, demonstrates the effects of $30 \mu \mathrm{M}$ indomethacin in combination with $10 \mathrm{ng} / \mathrm{ml} \mathrm{TNF} \alpha$; and the fine-hatched bar, labeled INDO, represents the percentage obtained after a $24 \mathrm{hr}$ treatment with $30 \mu \mathrm{M}$ indomethacin alone. $B$, The enhancement of labeling by $\mathrm{CPGI}_{2}, \mathrm{TNF}$, and a combination of $\mathrm{CPGI}_{2}$ and TNF. The fine-hatched bar, labeled $C P G I_{2}$, represents the percentage after a $24 \mathrm{hr}$ pretreatment with $10 \mathrm{nM} \mathrm{CPGI}_{2}$; the coarse-hatched bar, labeled $T N F$, shows the percentage after a 24 treatment with $10 \mathrm{ng} / \mathrm{ml} \mathrm{TNF} \alpha$; and the fine-hatched bar, labeled TNF $\mathrm{CPGI}_{2}$, illustrates the percentage obtained for the combined treatment with $10 \mathrm{nM} \mathrm{CPGI}$ and $10 \mathrm{ng} / \mathrm{ml} \mathrm{TNF} \alpha$. The asterisks indicate significant differences between the control and experimental treatments $(p<0.05)$.

\section{Tumor necrosis factor sensitizes the neuronal response to capsaicin}

The results presented above demonstrate that $\mathrm{TNF} \alpha$ increased the number of neurons that were labeled by cobalt after exposure to capsaicin. To further investigate the possibility that the increased number of positively labeled neurons resulted from a TNF $\alpha$-mediated increase in the sensitivity of these neurons to capsaicin, we obtained the response to focally applied capsaicin from a single neuron via the whole-cell patch-clamp recording

\section{CONTROL}

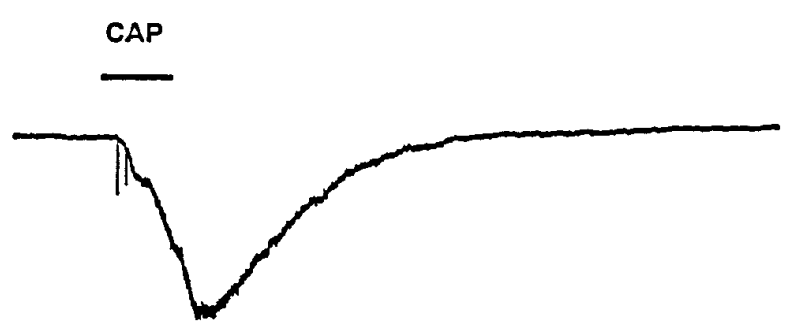

TNF

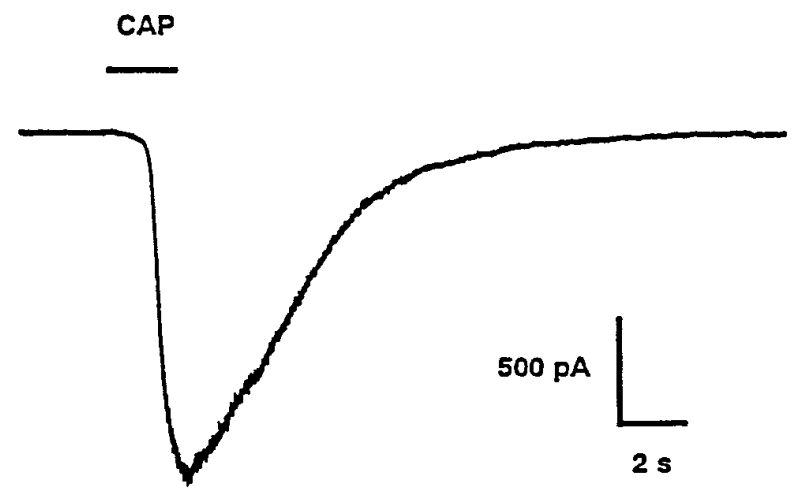

Figure 3. TNF $\alpha$ enhances the amplitude of the capsaicin response. The top panel illustrates a representative response to the focal application of $100 \mathrm{~nm}$ capsaicin obtained under control conditions. The bottom panel shows the response from a different neuron to the focal application of capsaicin after a $24 \mathrm{hr}$ treatment with $10 \mathrm{ng} / \mathrm{ml} \mathrm{TNF} \alpha$. The bars labeled $C A P$ indicate the timing and duration of the applications of capsaicin. Both neurons were held at $-60 \mathrm{mV}$; inward currents are shown as downward.

technique (Hamill et al., 1981). A representative response to capsaicin obtained under control conditions is illustrated in Figure 3 (top panel). At a holding potential of $-60 \mathrm{mV}$, the focal application of $100 \mathrm{~nm}$ capsaicin ( $2 \mathrm{sec}$ duration) elicited a peak inward current of $850 \mathrm{pA}$ that slowly recovered to baseline. At the peak of the response there was an increase in the membrane current noise, suggesting that this inward current resulted from the opening of capsaicin-gated ion channels. Then the cell was superfused for another 2 min with Ringer's solution to ensure complete recovery. At this point, the superfusate was changed to Ringer's containing $1 \mu \mathrm{M}$ capsaicin, for which a maximal inward current of $2300 \mathrm{pA}$ was elicited. In recordings from eight neurons under control conditions, the inward current elicited by $100 \mathrm{nM}$ capsaicin had an average value of $610 \pm 163 \mathrm{pA}$ (range 65-1238 $\mathrm{pA})$. Exposure of these neurons to $1 \mu \mathrm{M}$ capsaicin produced an average maximal response of $1701 \pm 311$ pA (range 700-3000 $\mathrm{pA})$. In comparison with the control recordings, the neuronal response to capsaicin was enhanced greatly after a $24 \mathrm{hr}$ treatment with $10 \mathrm{ng} / \mathrm{ml} \mathrm{TNF} \alpha$ (Fig. 3, bottom panel). In this representative neuron, a 2 sec pulse of $100 \mathrm{~nm}$ capsaicin applied focally elicited an inward current of $1725 \mathrm{pA}$; the bath application of $1 \mu \mathrm{M}$ capsaicin produced a maximal response of $2450 \mathrm{pA}$. After a $24 \mathrm{hr}$ treatment with $\mathrm{TNF} \alpha$, the average response to $100 \mathrm{~nm}$ capsaicin was $1446 \pm 339 \mathrm{pA}$ (range $400-4000 \mathrm{pA}, n=10$ ), whereas the average maximal response was $1898 \pm 387$ pA (range 600-4800 $\mathrm{pA})$. This large increase in the inward current evoked by the focal application of capsaicin after $\mathrm{TNF} \alpha$ treatment did not result from 


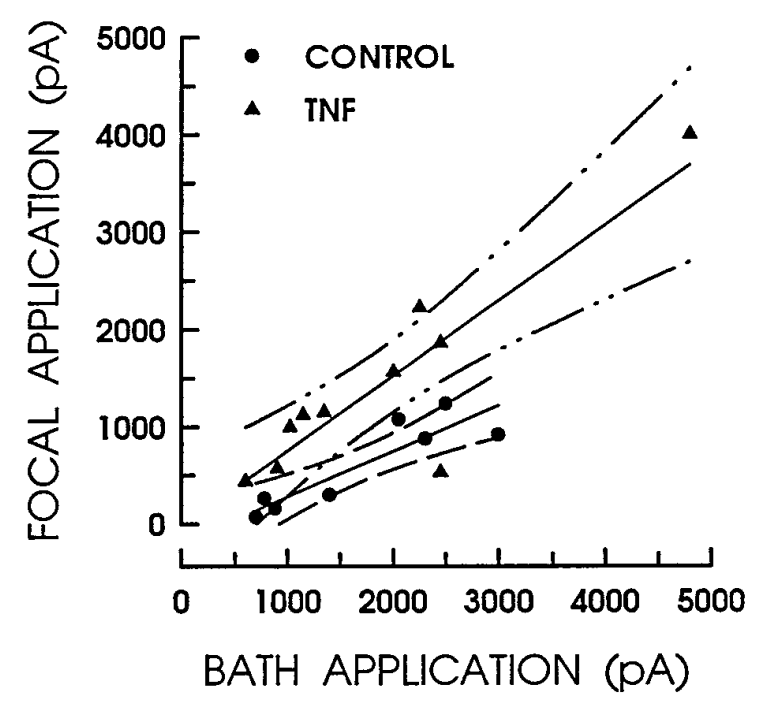

Figure 4. TNF $\alpha$ enhances the response to capsaicin without altering the maximal response. The amplitude of the response to the focal application of $100 \mathrm{~nm}$ capsaicin is plotted as a function of the maximal response obtained in that same neuron for the bath application of $1 \mu \mathrm{M}$ capsaicin. The filled circles represent those responses obtained under control conditions $(n=8)$, whereas the filled triangles illustrate the responses after a 24 $\mathrm{hr}$ treatment with $10 \mathrm{ng} / \mathrm{ml} \mathrm{TNF} \alpha(n=10)$. The lines through the points are the linear regressions in which the fitting parameters are listed in the text. The broken lines represent the 95\% confidence limits for each regression line.

an overall enhancement of the capsaicin response, because the average maximum response to $1 \mu \mathrm{M}$ capsaicin obtained under control conditions was not significantly different from that after $\mathrm{TNF} \alpha$ treatment.

The notion that TNF $\alpha$ enhanced the capsaicin sensitivity of sensory neurons is supported further by examining the response amplitudes to the focal application of $100 \mathrm{~nm}$ capsaicin as a function of the response amplitudes to the bath application of 1 $\mu \mathrm{M}$ capsaicin (i.e., the maximum response). As shown in Figure 4, the amplitudes of the responses obtained under control conditions are fit by a linear regression line having a slope of 0.47 and a Pearson's correlation coefficient of 0.90 . In contrast, after treatment with $\mathrm{TNF} \alpha$ the response amplitudes are larger and are now fit by a linear regression line having a slope of 0.77 and a correlation coefficient of 0.88 . Therefore, these results indicate that treatment with $\mathrm{TNF} \alpha$ heightened the sensitivity of sensory neurons to this excitatory agent without altering the magnitude of the maximal response.

The time course for sensitization of the capsaicin-evoked current by $\mathrm{TNF} \alpha$ was very similar to that observed for the cobaltlabeling studies. As shown in Figure 5, the capsaicin response was enhanced by nearly twofold after a $4 \mathrm{hr}$ treatment with $10 \mathrm{ng} / \mathrm{ml}$ $\mathrm{TNF} \alpha$. Likewise, after 12 and $24 \mathrm{hr}$ treatments with $10 \mathrm{ng} / \mathrm{ml}$ $\mathrm{TNF} \alpha$, the relative amplitudes of the capsaicin-elicited current were doubled. However, an acute $10 \mathrm{~min}$ exposure to TNF $\alpha$ had no significant effect on the capsaicin response. In our previous studies, a 10 min exposure to $\mathrm{PGE}_{2}$ was sufficient to produce a maximal enhancement in the number of action potentials evoked by bradykinin (Nicol and Cui, 1994; Cui and Nicol, 1995). Therefore, these results suggest that $\mathrm{TNF} \alpha$ does not have an immediate action on the sensitivity of these neurons to capsaicin, but, rather, the processes mediating this enhancement require a period of hours to become effective.

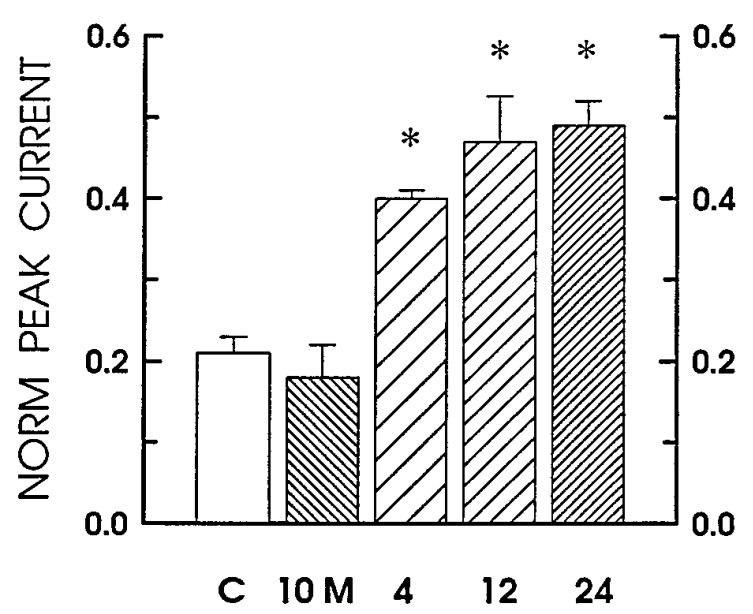

Figure 5. Time course for the TNF $\alpha$-induced sensitization of the capsaicin response. The bars represent the current elicited by the focal application of $100 \mathrm{~nm}$ capsaicin that was normalized to the maximal response obtained to the bath application of $1 \mu \mathrm{M}$ capsaicin for different experimental treatments. The open bar represents untreated neurons under control conditions $(n=9)$. The hatched bar, labeled $10 \mathrm{M}$, represents the currents obtained after a $10 \mathrm{~min}$ exposure to $10 \mathrm{ng} / \mathrm{ml} \mathrm{TNF} \alpha(n=5)$. The coarse-, medium-, and fine-hatched bars denote those currents recorded after $4(n=5), 12(n=5)$, and $24(n=5) \mathrm{hr}$ treatments, respectively, with $10 \mathrm{ng} / \mathrm{ml} \mathrm{TNF} \alpha$.

The neuronal responses to capsaicin obtained under control conditions and after $\mathrm{TNF} \alpha$ treatment from two different sets of neurons are summarized in Figure $6 A$. After normalization, the application of $100 \mathrm{nM}$ capsaicin under control conditions produced an average response that was $0.32 \pm 0.05(n=8)$ of the maximal response. In those sensory neurons treated with $10 \mathrm{ng} / \mathrm{ml}$ $\mathrm{TNF} \alpha$ for $24 \mathrm{hr}$, the average response to $100 \mathrm{~nm}$ capsaicin was increased significantly to $0.77 \pm 0.07(n=10)$ of the maximal response. Thus, TNF $\alpha$ produced a greater than twofold enhancement in the sensitivity of sensory neurons to the focal application of capsaicin.

As with the cobalt-labeling studies, the possible contribution of cyclo-oxygenase products to the TNF $\alpha$ sensitization was examined by pretreating the neuronal cultures with $30 \mu \mathrm{M}$ indomethacin before the addition of $10 \mathrm{ng} / \mathrm{ml} \mathrm{TNF} \alpha$. As shown in Figure $6 A$, indomethacin blocked the TNF $\alpha$-induced increase in the response to $100 \mathrm{nM}$ capsaicin such that, after exposure to indomethacin and $\mathrm{TNF} \alpha$, the average fractional response was only $0.36 \pm 0.07(n=$ 4) of the maximum and was similar to the control value of 0.32 . A $24 \mathrm{hr}$ treatment with $30 \mu \mathrm{M}$ indomethacin alone had no significant effect on the average fractional response to $100 \mathrm{~nm}$ capsaicin $(0.36 \pm 0.06, n=4)$. At this concentration, indomethacin inhibits both the constitutively active cyclo-oxygenase- 1 (COX-1) and the inducible cyclo-oxygenase-2 [COX-2; Masferrer et al. (1994); Seibert et al. (1994b); but see Meade et al. (1993)]. In a separate series of experiments, a selective inhibitor of COX-2, SC-236 (Peter Isakson, personal communication), was used to distinguish which isoform mediated the $\mathrm{TNF} \alpha$-induced sensitization. This inhibitor of COX-2 has an activity on human enzymes with an $\mathrm{IC}_{50}$ of $0.01 \mu \mathrm{M}$ for COX-2 and $18 \mu \mathrm{M}$ for COX-1 (T. D. Penning, J. J. Talley, S. R. Bertenshaw, J. S. Carter, P. W. Collins, S. Docter, M. J. Graneto, L. F. Lee, J. W. Malecha, J. M. Miyashiro, R. S. Rogers, D. J. Rogier, S. S. Yu, G. D. Anderson, J. N. Cogburn, S. A. Gregory, C. M. Koboldt, W. E. Perkins, K. Seibert, A. W. Veenhuizen, Y. Zhang, P. C. Isakson, unpublished data). In the

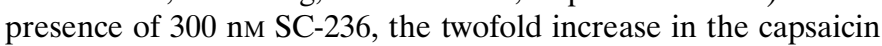


A.

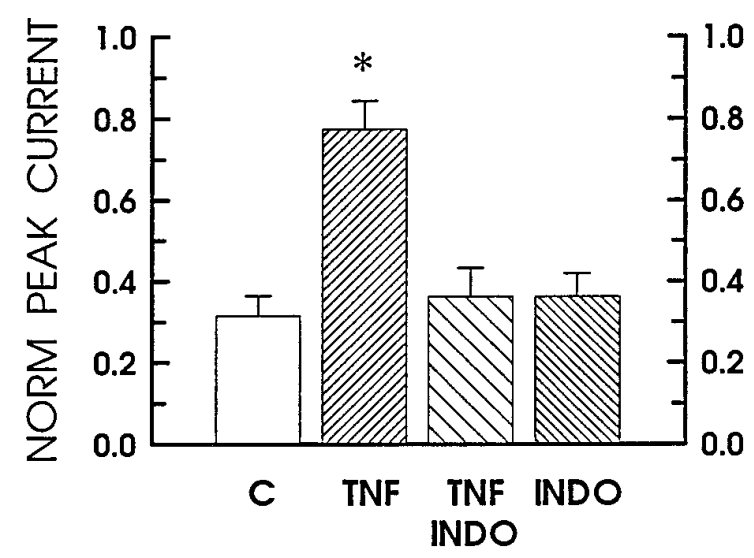

B.

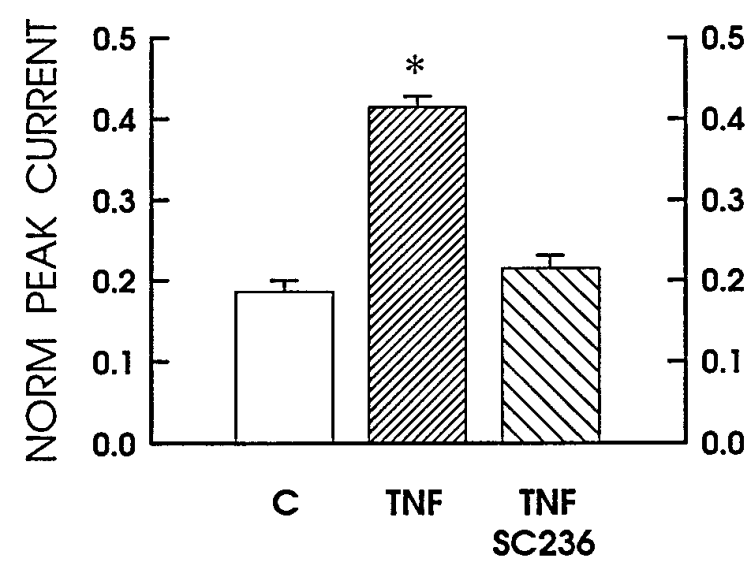

Figure 6. TNF $\alpha$ enhancement of the capsaicin response is blocked by inhibition of cyclo-oxygenase. $A$, The sensitizing effects of TNF $\alpha$ on the normalized response to capsaicin and its inhibition by indomethacin. The focal response to $100 \mathrm{nM}$ capsaicin is expressed as the fraction of the maximal response obtained with the bath application of $1 \mu \mathrm{M}$ capsaicin. The bars represent the following experimental conditions: the control is shown as the open bar $(n=8)$; the fine-hatched bar, labeled $T N F$, is after a $24 \mathrm{hr}$ treatment with $10 \mathrm{ng} / \mathrm{ml} \mathrm{TNF} \alpha(n=10)$; the coarse-hatched bar is after treatment with $30 \mu \mathrm{M}$ indomethacin and $10 \mathrm{ng} / \mathrm{ml} \mathrm{TNF} \alpha(n=4)$; and the fine-hatched bar, labeled INDO, is after a $24 \mathrm{hr}$ treatment with $30 \mu \mathrm{M}$ indomethacin alone $(n=4) . B$ demonstrates in another set of sensory neurons inhibition of the TNF $\alpha$-induced sensitization by treatment with the selective COX-2 inhibitor SC-236. The open bar represents the untreated control neurons $(n=3)$. The fine-hatched bar represents results obtained after a $24 \mathrm{hr}$ treatment with $10 \mathrm{ng} / \mathrm{ml} \operatorname{TNF} \alpha(n=5)$; the coarse-hatched bar is after treatment with $300 \mathrm{nM} \mathrm{SC}-236$ and $10 \mathrm{ng} / \mathrm{m}$ $\mathrm{TNF} \alpha(n=5)$. The asterisks indicate statistical significance at $p<0.05$.

sensitivity produced by TNF $\alpha$ was blocked completely (Fig. 6B). In another series of experiments, $10 \mu \mathrm{M} \mathrm{SC}-236$ also produced a complete suppression of the TNF $\alpha$-mediated enhancement (from $0.49 \pm 0.03$ to $0.21 \pm 0.02)$, whereas SC-236 alone had no effect on the response to capsaicin $(0.26 \pm 0.03$ vs $0.22 \pm 0.02$ for the control; data not shown). Therefore, using both population studies involving cobalt-labeling as well as electrophysiological studies examining the response obtained from a single neuron, we show results that indicate that pretreatment with $\mathrm{TNF} \alpha$ enhanced the sensitivity of sensory neurons to the excitation elicited by capsaicin. Furthermore, the delayed time course of sensitization likely results from a TNF $\alpha$-mediated induction of COX-2 that ultimately leads to the production of prostaglandins.

\section{DISCUSSION}

The results presented in this study demonstrate that $\mathrm{TNF} \alpha$, but not IL-1 $\beta$, can sensitize isolated sensory neurons to the excitation produced by capsaicin. With the use of two different assays of neuronal sensitivity, $\mathrm{TNF} \alpha$ increased the number of neurons labeled by cobalt after exposure to capsaicin as well as the amplitude of the inward current evoked by the focal application of capsaicin to a single neuron. Although the cellular pathways mediating this sensitization are not well characterized, it seems unlikely that the increased responsiveness results from an increase in the total number of capsaicin receptors, because the maximal inward current elicited by $1 \mu \mathrm{M}$ capsaicin was similar in the absence or presence of TNF $\alpha$.

The TNF $\alpha$-induced sensitization likely is mediated by prostaglandins, because enhancement of the capsaicin response was blocked by both indomethacin, a nonselective inhibitor of cyclooxygenase, and SC-236, a specific inhibitor of COX-2. These results suggest that $\mathrm{TNF} \alpha$ somehow leads to the induction and activation of COX-2 to release prostaglandins and, thus, enhances the response to capsaicin. Indeed, sensory neurons grown in culture can synthesize, from labeled arachidonic acid, many different prostanoids, most prominently $\mathrm{PGE}_{2}$, with smaller levels of 6-keto $\mathrm{PGF}_{1 \alpha}$ (a breakdown product of $\mathrm{PGI}_{2}$ ), $\mathrm{PGD}_{2}$, and $\mathrm{PGF}_{2 \alpha}$ (Vasko et al., 1994). Also, these sensory neurons were labeled heavily by a nonspecific antibody to cyclo-oxygenase (Vasko et al., 1994). Thus, sensory neurons express cyclo-oxygenase that is capable of generating prostaglandins. It is well documented that prostaglandins, especially $\mathrm{PGE}_{2}$ and $\mathrm{PGI}_{2}$ (prostacyclin), play critical roles in the initiation of the heightened sensitivity to stimulation in both in vivo and in vitro models of neurogenic inflammation (Davies et al., 1984; Higgs et al., 1984). This notion is supported further by our observations that the number of cobalt-labeled neurons was increased by approximately twofold after a $24 \mathrm{hr}$ pretreatment with the proinflammatory prostaglandin $\mathrm{CPGI}_{2}$. Likewise, exposure to $\mathrm{CPGI}_{2}$ on a much shorter time scale sensitizes isolated sensory neurons. Previously, we reported that pretreatment of sensory neurons with a higher concentration of $\mathrm{CPGI}_{2}(1 \mu \mathrm{M})$ for only $20 \mathrm{~min}$ produced a threefold increase the number of cobalt-labeled cells by capsaicin (Hingtgen and Nicol, 1994).

Currently, the intracellular transduction cascades linking the $\mathrm{TNF} \alpha$ receptor and activation of cyclo-oxygenase are unknown. Recent evidence indicates that exposure to inflammatory mediators stimulates cyclo-oxygenase activity; however, the increased activity is limited to the inducible isoform COX-2 (Fu et al., 1990; Kujubu et al., 1991; O'Banion et al., 1991). Treatment with proinflammatory agents (Crofford et al., 1994; Masferrer et al., 1994; Seibert et al., 1994a,b; Feng et al., 1995) or tissue injury (Pritchard et al., 1994) induces the synthesis of COX-2 (prostaglandin $\mathrm{G} / \mathrm{H}$ synthase 2 ) but has no effect on the constitutively active isoform COX-1 (prostaglandin $\mathrm{G} / \mathrm{H}$ synthase 1). These observations indicate that it is the induction of COX-2, rather than increased activity of $\mathrm{COX}-1$, which mediates the release of prostaglandins during the inflammatory response. Indeed, COX-2 is expressed in synovial tissues isolated from patients with rheumatoid arthritis, and when explants of these synovial tissues are grown in culture, IL- $1 \beta$ significantly increases the mRNA level of 
COX-2, but not COX-1 (Crofford et al., 1994). The notion that $\mathrm{TNF} \alpha$ promotes the induction of COX-2 in sensory neurons is supported by two of our findings. First, our results demonstrate that selective inhibition of COX-2 with the compound SC-236 prevents the TNF $\alpha$-induced sensitization of the capsaicin response. Second, TNF $\alpha$ does not have an immediate action on the capsaicin sensitivity of these neurons but, rather, requires $\sim 4 \mathrm{hr}$ to become effective. This time course of cytokine action is supported by recent observations in which a significant increase in the relative expression of COX-2 mRNA was found $3 \mathrm{hr}$ after producing carrageenan-induced inflammation in the paw of a rat (Seibert et al., 1994b). Also, in the isolated rat trachea, the capsaicin-evoked release of CGRP was potentiated after a $5 \mathrm{hr}$ exposure to either TNF $\alpha$ or IL- $1 \beta$; however, there was no effect after $2 \mathrm{hr}$ (Hua et al., 1996). When taken together, experimental observations indicate that proinflammatory mediators have no significant effect on the levels or activity of COX-1; therefore, it seems highly likely that the enhanced sensitivity to capsaicin results from the ability of $\mathrm{TNF} \alpha$ to induce the synthesis of COX-2.

In many ways the physiological actions of TNF $\alpha$ and IL- $1 \beta$ are believed to be quite similar (Dinarello, 1987; Le and Vilček, 1987; Arend and Dayer, 1990). For example, studies using behavioral measures for the perception of noxious stimuli in intact animals report that injection of either $\mathrm{TNF} \alpha$ or IL- $1 \beta$ produces a hyperalgesic response (Ferreira et al., 1988; Schweizer et al., 1988; Follenfant et al., 1989; Cunha et al., 1992). In the intact animals, the cytokine-induced sensitization was blocked by pretreatment with indomethacin, also indicating a role for cyclo-oxygenase products. Similarly, in the isolated and perfused rat trachea, lipopolysaccharide, IL- $1 \beta$, or $\mathrm{TNF} \alpha$ facilitated the release of CGRP that was evoked by stimulation with capsaicin (Hua et al., 1996). These results, then, suggest that the threshold had been lowered, wherein TNF $\alpha$ or IL- $1 \beta$ had a sensitizing effect on the sensory afferent nerves, responding to the noxious or chemical stimulation. It is, however, curious that $\mathrm{TNF} \alpha$, but not IL- $1 \beta$, sensitizes the isolated sensory neurons grown in culture to the excitation produced by capsaicin. Compared with TNF $\alpha$, IL- $1 \beta$ had no significant effect on the number of cobalt-labeled neurons, even at a relatively high concentration $(50 \mathrm{ng} / \mathrm{ml})$. The lack of an IL- $1 \beta$ effect on the excitability of sensory neurons is supported by a similar finding in which, in recordings from cultured sympathetic neurons isolated from rat superior cervical ganglia, the calcium current was potentiated by long-term exposures ( $>4 \mathrm{hr})$ to $\mathrm{TNF} \alpha$, but not to IL-1 $\beta$ (Soliven and Albert, 1992). Therefore, our observations are consistent with the notion that the sensitizing effects of IL- $1 \beta$ observed in the intact animal or isolated tissue might result from an IL- $1 \beta$-induced production of a secondary mediator released from other cell types rather than from a direct action of IL- $1 \beta$ on the sensory neuron.

The intracellular transduction cascades that mediate the prostaglandin-induced sensitization are poorly understood. Our previous observations suggest that these isolated sensory neurons grown in culture are an excellent model system in which to investigate the regulatory pathways activated by proinflammatory prostaglandins. Acute treatment with $\mathrm{PGE}_{2}$ enhances the excitability of isolated sensory neurons grown in culture in a manner that is similar to that observed in both in vivo and in vitro animal models of pain and neurogenic inflammation. For example, a 10 min pretreatment with $1 \mu \mathrm{M} \mathrm{PGE}_{2}$ produced a threefold increase in the number of action potentials elicited by the focal application of bradykinin (Nicol and Cui, 1994). Similarly, in the intact animal, the frequency of action potentials recorded from $\mathrm{C}$-fibers in response to bradykinin was increased after the application of

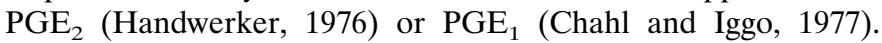
Furthermore, acute treatment with either $\mathrm{PGE}_{2}$ or $\mathrm{CPGI}_{2}$ enhanced the bradykinin-evoked release of substance $\mathrm{P}$ and calcitonin gene-related peptide from isolated sensory neurons grown in culture (Hingtgen and Vasko, 1994; Vasko et al., 1994). These neuroactive peptides have been demonstrated to be important mediators of neurogenic inflammation (Cuello, 1987; Foreman, 1987).

In a manner analogous to short-term applications, our current findings describing the effects of sustained treatment ( $24 \mathrm{hr}$ ) with $\mathrm{TNF} \alpha$ and $\mathrm{CPGI}_{2}$ suggest that isolated sensory neurons grown in culture may prove to be a useful model system in which to explore how prolonged exposure to mediators associated with chronic inflammation alters the pathways controlling cellular sensitivity and excitability. Investigation of the cellular mechanisms whereby proinflammatory cytokines, such as $\mathrm{TNF} \alpha$, produce transcriptional changes that lead to either the induction or downregulation of various enzyme systems, such as COX-2, would enhance our understanding of the role played by sensory neurons in the maintenance of neurogenic inflammation. Indeed, patients afflicted with rheumatoid arthritis (a condition associated with chronic inflammation of the joints) have elevated levels of inflammatory cytokines and prostaglandins in their synovial fluids as well as a tendency for chronic pain in those joints (Arend and Dayer, 1990; Feldman et al., 1990; Bhoola et al., 1992; Konttinen et al., 1994).

In conclusion, the proinflammatory cytokine, $\mathrm{TNF} \alpha$, directly enhances the sensitivity of sensory neurons to the chemical excitatory agent capsaicin via a cyclo-oxygenase-dependent pathway. It is possible that this cytokine-mediated sensitization may be part of a more global mechanism whereby regulatory pathways associated with the immune system modulate the excitability of the nervous system.

\section{REFERENCES}

Arend WP, Dayer J-M (1990) Cytokines and cytokine inhibitors or antagonists in rheumatoid arthritis. Arthritis Rheum 33:305-315.

Baccaglini PI, Hogan PG (1983) Some rat sensory neurons in culture express characteristics of differentiated pain sensory cells. Proc Natl Acad Sci USA 80:594-598.

Bevan S, Forbes CA (1988) Membrane effects of capsaicin on rat dorsal root ganglion neurones in cell culture. J Physiol (Lond) 398:28P.

Bhoola KD, Elson CJ, Dieppe PA (1992) Kinins-key mediators in inflammatory arthritis. Br J Rheumatol 31:509-518.

Burch RM, Tiffany CW (1989) Tumor necrosis factor causes amplification of arachidonic acid metabolism in response to interleukin 1, bradykinin, and other agonists. J Cell Physiol 141:85-89.

Burch RM, Connor JR, Axelrod J (1988) Interleukin 1 amplifies receptor-mediated activation of phospholipase $\mathrm{A}_{2}$ in $3 \mathrm{~T} 3$ fibroblasts. Proc Natl Acad Sci USA 85:6306-6309.

Chang J, Gilman SC, Lewis AJ (1986) Interleukin 1 activates phospholipase $\mathrm{A}_{2}$ in rabbit chondrocytes: a possible signal for IL-1 action. J Immunol 136:1283-1287.

Chahl LA, Iggo A (1977) The effects of bradykinin and prostaglandin $\mathrm{E}_{1}$ on rat cutaneous afferent nerve activity. Br J Pharmacol 59:343-347.

Crofford LJ, Wilder RL, Ristimäki AP, Sano H, Remmers EF, Epps HR, Hla T (1994) Cyclo-oxygenase-1 and -2 expression in rheumatoid synovial tissues. Effects of interleukin- $1 \beta$ : phorbol ester and corticosteroids. J Clin Invest 93:1095-1101.

Cuello AC (1987) Peptides as modulators in primary sensory neurons. Neuropharmacology 26:971-979.

Cui M, Nicol GD (1995) Cyclic AMP mediates the prostaglandin $\mathrm{E}_{2-}$ induced potentiation of bradykinin excitation in rat sensory neurons. Neuroscience 66:459-466.

Cunha FQ, Poole S, Lorenzetti BB, Ferreira SH (1992) The pivotal role of tumour necrosis factor $\alpha$ in the development of inflammatory hyperalgesia. Br J Pharmacol 107:660-664.

Davies P, Bailey PJ, Goldenberg MM, Ford-Hutchinson AW (1984) The 
role of arachidonic acid oxygenation products in pain and inflammation. Annu Rev Immunol 2:335-357.

Dayer J-M, Demczuk S (1984) Cytokines and other mediators in rheumatoid arthritis. Springer Semin Immunopathol 7:387-413.

Dayer J-M, Beutler B, Cerami A (1985) Cachectin/tumor necrosis factor stimulates collagenase and prostaglandin $E_{2}$ production by human synovial cells and dermal fibroblasts. J Exp Med 162:2163-2168.

Dinarello CA (1987) The biology of interleukin 1 and comparison to tumor necrosis factor. Immunol Lett 16:227-232.

Dinarello CA (1991) The proinflammatory cytokines interleukin 1 and tumor necrosis factor and treatment of the septic shock syndrome. J Infect Dis 163:1177-1184.

Feldman M, Brennan FM, Chantry D, Haworth C, Turner M, Abney E, Buchan G, Barrett K, Barkley D, Chu A, Field M, Maini RN (1990) Cytokine production in the rheumatoid joint: implications for treatment. Ann Rheum Dis 49:480-486.

Feng L, Xia Y, Garcia GE, Hwang D, Wilson CB (1995) Involvement of reactive oxygen intermediates in cyclo-oxygenase-2 expression induced by interleukin-1, tumor necrosis factor- $\alpha$, and lipopolysaccharide. J Clin Invest 95:1669-1675.

Ferreira SH, Nakamura M, Salete de Abreu Castro M (1978) The hyperalgesic effects of prostacyclin and prostaglandin $\mathrm{E}_{2}$. Prostaglandins 16:31-37.

Ferreira SH, Lorenzetti BB, Bristow AF, Poole S (1988) Interleukin $1 \beta$ as a potent hyperalgesic agent antagonized by a tripeptide analogue. Nature 334:698-700.

Follenfant RL, Nakamura-Craig M, Henderson B, Higgs GA (1989) Inhibition by neuropeptides of interleukin- $\beta$-induced prostaglandinindependent hyperalgesia. Br J Pharmacol 98:41-43.

Foreman JC (1987) Peptides and neurogenic inflammation. Br Med Bull 43:386-400.

Fu J-Y, Masferrer JL, Seibert K, Raz A, Needleman P (1990) The induction and suppression of prostaglandin $\mathrm{H}_{2}$ synthase (cyclooxygenase) in human monocytes. J Biol Chem 265:16737-16740.

Hamill OP, Marty A, Neher E, Sakmann B, Sigworth FJ (1981) Improved patch-clamp techniques for high-resolution current recording from cells and cell-free membrane patches. Pflügers Arch 391:85-100.

Handwerker HO (1976) Influences of algogenic substances and prostaglandins on the discharges of unmyelinated cutaneous nerve fibers identified as nociceptors. Adv Pain Res Ther 1:41-45.

Heppelmann B, Schaible H-G, Schmidt RF (1985) Effects of prostaglandins $E_{1}$ and $E_{2}$ on the mechanosensitivity of group III afferents from normal and inflamed cat knee joints. Adv Pain Res Ther 9:91-101.

Heyman I, Rang HP (1985) Depolarizing responses to capsaicin in a subpopulation of rat dorsal root ganglion cells. Neurosci Lett 56:69-75.

Higgs GA, Moncada S, Vane JR (1984) Eicosanoids in inflammation. Ann Clin Res 16:287-299.

Hingtgen CM, Nicol GD (1994) Carba prostacyclin enhances the capsaicin-induced cobalt loading of rat sensory neurons grown in culture. Neurosci Lett 173:99-102.

Hingtgen CM, Vasko MR (1994) Prostacyclin enhances the evokedrelease of substance $\mathrm{P}$ and calcitonin gene-related peptide from rat sensory neurons. Brain Res 655:51-60.

Holzer P (1991) Capsaicin: cellular targets, mechanisms of action, and selectivity for thin sensory neurons. Pharmacol Rev 43:143-201.

Hua X-Y, Chen P, Fox A, Myers RR (1996) Involvement of cytokines in lipopolysaccharide-induced facilitation of CGRP release from capsaicin-sensitive nerves in the trachea: studies with interleukin- $1 \beta$ and tumor necrosis factor- $\alpha$. J Neurosci 16:4742-4748.

Kimball ES (1991) Involvement of cytokines in neurogenic inflammation. In: Cytokines and inflammation (Kimball ES, ed), pp 169-189. Boston: CRC.

Konttinen YT, Kemppinen P, Segerberg M, Hukkanen M, Rees R, San- tavirta S, Sorsa T, Pertovaara A, Polak JM (1994) Peripheral and spinal neural mechanisms in arthritis, with particular reference to treatment of inflammation and pain. Arthritis Rheum 37:965-982.

Kujubu DA, Fletcher BS, Varnum BC, Lim RW, Herschman HR (1991) TIS10, a phorbol ester tumor promoter-inducible mRNA from Swiss $3 \mathrm{~T} 3$ cells, encodes a novel prostaglandin synthase/cyclo-oxygenase homologue. J Biol Chem 266:12866-12872.

Le J, Vilček J (1987) Tumor necrosis factor and interleukin 1: cytokines with multiple overlapping biological activities. Lab Invest 56:234-248.

Marsh SJ, Stansfeld CE, Brown DA, Davey R, McCarthy D (1987) The mechanism of action of capsaicin on sensory C-type neurons and their axons in vitro. Neuroscience 23:275-289.

Masferrer JL, Zweifel BS, Manning PT, Hauser SD, Leahy KM, Smith WG, Isakson PC, Seibert K (1994) Selective inhibition of inducible cyclo-oxygenase 2 in vivo is antiinflammatory and nonulcerogenic. Proc Natl Acad Sci USA 91:3228-3232.

Meade EA, Smith WL, DeWitt DL (1993) Differential inhibition of prostaglandin endoperoxide synthase (cyclo-oxygenase) isozymes by aspirin and other non-steroidal anti-inflammatory drugs. J Biol Chem 268:6610-6614.

Mense S (1981) Sensitization of group IV muscle receptors to bradykinin by 5-hydroxytryptamine and prostaglandin $\mathrm{E}_{2}$. Brain Res 225:95-105.

Nicol GD, Cui M (1994) Prostaglandin $E_{2}$ enhances bradykinin activation of embryonic rat sensory neurones. J Physiol (Lond) 480:485-492.

O'Banion MK, Sadowski HB, Winn V, Young DA (1991) A serum- and glucocorticoid-regulated 4-kilobase mRNA encodes a cyclo-oxygenaserelated protein. J Biol Chem 266:23261-23267.

Pateromichelakis S, Rood JP (1982) Prostaglandin $E_{1}$-induced sensitization of A $\delta$ moderate pressure mechanoreceptors. Brain Res 232:89-96.

Pritchard Jr KA, O'Banion MK, Miano JM, Vlasic N, Bhatia UG, Young DA, Stemerman MB (1994) Induction of cyclo-oxygenase-2 in rat vascular smooth muscle cells in vitro and in vivo. $\mathrm{J}$ Biol Chem 269:8504-8509.

Raz A, Wyche AW, Siegel N, Needleman P (1988) Regulation of fibroblast cyclo-oxygenase synthesis by interleukin-1. J Biol Chem 263:3022-3028.

Salmon JA, Higgs GA (1987) Prostaglandins and leukotrienes as inflammatory mediators. Br Med Bull 43:285-296.

Schweizer A, Feige U, Fontana A, Müller K, Dinarello CA (1988) Interleukin-1 enhances pain reflexes. Mediations through increased prostaglandin E2 levels. Agents Actions 25:246-251.

Seibert K, Masferrer J, Zhang Y, Gregory S, Olson G, Hauser S, Leahy K, Perkins W, Lee L, Isakson P (1994a) Mediation of inflammation by cyclo-oxygenase-2. Agents Actions Suppl 46:41-50.

Seibert K, Zhang Y, Leahy K, Hauser S, Masferrer J, Perkins W, Lee L, Isakson P (1994b) Pharmacological and biochemical demonstration of the role of cyclo-oxygenase 2 in inflammation and pain. Proc Natl Acad Sci USA 91:12013-12017.

Smith WL (1992) Prostanoid biosynthesis and mechanisms of action. Am J Physiol 263:F181-F191.

Soliven B, Albert J (1992) Tumor necrosis factor modulates $\mathrm{Ca}^{2+}$ currents in cultured sympathetic neurons. J Neurosci 12:2665-2671.

Treede R-F, Meyer RA, Raja SN, Campbell JN (1992) Peripheral and central mechanisms of cutaneous hyperalgesia. Prog Neurobiol 38:397-421.

Vasko MR, Campbell WB, Waite KJ (1994) Prostaglandin $E_{2}$ enhances bradykinin-stimulated release of neuropeptides from rat sensory neurons in culture. J Neurosci 14:4987-4997.

Winter J (1987) Characterization of capsaicin-sensitive neurones in adult rat dorsal root ganglion cultures. Neurosci Lett 80:134-140.

Wood JN, Winter J, James IF, Rang HP, Yeats J, Bevan S (1988) Capsaicin-induced ion fluxes in dorsal root ganglion cells in culture. J Neurosci 8:3208-3220. 